Research Article

Young Chel Kwun, Manzoor Ahmad Zahid, Waqas Nazeer, Ashaq Ali, Maqbool Ahmad, and Shin Min Kang*

\title{
On the Zagreb polynomials of benzenoid systems
}

https://doi.org/10.1515/phys-2018-0092

Received May 26, 2018; accepted Aug 28, 2018

\begin{abstract}
Topological indices play significant role in determining properties of chemical compound. Algebraic polynomials help to compute topological indices of studied chemical compounds. Benzenoid systems are used mainly as an intermediate to make other chemicals. In this report we aim to compute Zagreb polynomials of zigzag, rhombic, triangular, hourglass and jagged-rectangle benzenoid systems.
\end{abstract}

Keywords: topological index, Zagreb polynomial, benzenoid system

PACS: 81.05.-t, 81.07.Nb

\section{Introduction}

Chemical reaction network theory deals with an attempt to model the behavior of real world chemical systems. From the very beginning of its foundation, it is crucial for research community; especially due to its importance in two branches i.e. biochemistry and theoretical chemistry. It

\footnotetext{
`Corresponding Author: Shin Min Kang: Department of Mathematics and Research Institute of Natural Science, Gyeongsang National University, Jinju 52828, Korea; Center for General Education, China Medical University, Taichung 40402, Taiwan;

Email: smkang@gnu.ac.kr

Young Chel Kwun: Department of Mathematics, Dong-A University, Busan49315, Korea; Email: yckwun@dau.ac.kr

Manzoor Ahmad Zahid: COMSATS institute of Information Technology, Sahiwal Campus, Sahiwal Pakistan;

Email: manzoor@ciitshiwal.edu.pk

Waqas Nazeer: Division of Science and Technology, University of Education, Lahore 54000, Pakistan;

Email: nazeer.waqas@ue.edu.pk

Ashaq Ali: Department of Mathematics, University of Engineering and Technology, Lahore Pakistan;

Email: usmansafdar32@gmail.com

Maqbool Ahmad: Department of Mathematics, University of Engineering and Technology, Lahore Pakistan;

Email: mustafa@uet.edu.pk
}

also has a significant place in pure mathematics particularly due to its mathematical structures.

Cheminformatics is an upcoming and progressive area that deals with the relationships of quantitative structure activity (QSAR), structure property (QSPR) and also predicts the biochemical activities and properties of chemical compounds (see [1, 2]). In these studies, for the prediction of bioactivity of the chemical compounds, some physicochemical properties and topological indices are used [3,4].

Mathematical chemistry is a branch, which discusses the chemical structures with the aid of mathematical tools. Molecular graph is a simple graph in chemical graph theory. Such a graph consists of atoms and chemical bonds, which are represented by vertices and edges, respectively. For the connection of vertex set $V(G)$ and edge set $E(G)$ of a graph, there must be an existence of linking between any pair of vertices in $G$. The distance between two vertices $u$ and $v$ is represented as $d(u, v)$ and it is the shortest length between $u$ and $v$ in graph $G$. The degree of vertex is basically the number of vertices of $G$, adjacent to given vertex $v$ and will be represented by $d(v)$.

Many algebraic polynomials have fruitful exercises in chemistry such as Hosoya polynomial, which helps to compute some important distance based topological indices. Degree based topological indices are determined from M-polynomial, which was introduced in 2015. This polynomial has been on the basic areas of interest in computational aspects of substances. Many topological indices can be calculated by using M-polynomial [5, 8]. The topological index of a molecule can be used to quantify the molecular structure and its branches design in many ways. To be simple, the topological index can be considered as a function that assigns each molecular structure to real number $[9,10]$. Boiling point, heat of evaporation, heat of formation, chromatographic retention times, surface tension, vapor pressure, etc. can be predicted by using topological indices. The first and the second Zagreb indices are degree based graph invariants, which have been studied extensively since the 1970's. In 1998, Bollobás and Erdős introduced the general Randić index, which is the generalization of Randić index and has been widely studied by both mathematicians and theoretical chemists. Another variant of Randić index is the harmonic index and 
its usefulness for computing the heatof formation of alkanes $[11,12]$. The graphs considered in this paper are simply connected.

In 1972, the quantities $M_{1}$ and $M_{2}$ were found to occur within certain approximate expressions for the total $\pi$-electron energy [13]. In 1975, these graph invariants were proposed to be the measures of branching of the carbonatom skeleton [14]. The name "Zagreb index" (or more precisely, "Zagreb group index") seems to be used in the review article for the first time [15]. For details of the mathematical theory and chemical applications of the Zagreb indices, see surveys [16-19] and papers [20-28].

$$
M_{1}(G)=\sum_{u v \in E(G)}\left(d_{u}+d_{v}\right)
$$

and

$$
M_{2}(G)=\sum_{u v \in E(G)}\left(d_{u} \times d_{v}\right) .
$$

Considering the Zagreb indices, Fath-Tabar [22] defined the first and the second Zagreb polynomials as

$$
M_{1}(G, x)=\sum_{u v \in E(G)} x^{d_{u}+d_{v}}
$$

and

$$
M_{2}(G, x)=\sum_{u v \in E(G)} x^{d_{u} \cdot d_{v}} .
$$

The properties of the first and the second Zagreb polynomials for some chemical structures have been studied in the literature $[29,30]$.

The third Zagreb index is defined as:

$$
M_{3}(G)=\sum_{u v \in E(G)}\left|d_{u}-d_{v}\right| .
$$

This graph invariant is also known as irregularity of G, see Ref. [31-33].

The third Zagreb polynomial is defined as:

$$
M_{3}(G, x)=\sum_{u v \in E(G)} x^{\left|d_{u}-d_{v}\right|} .
$$

In the year 2016 [34], following Zagreb type polynomials were defined

$$
\begin{aligned}
& M_{4}(G, x)=\sum_{u v \in E(G)} x^{d_{u}\left(d_{u}+d_{v}\right)} \\
& M_{5}(G, x)=\sum_{u v \in E(G)} x^{d_{v}\left(d_{u}+d_{v}\right)}
\end{aligned}
$$

$$
\begin{gathered}
M_{a, b}(G, x)=\sum_{u v \in E(G)} x^{a d_{u}+b d_{v}} \\
M_{a, b}^{\prime}(G, x)=\sum_{u v \in E(G)} x^{\left(d_{u}+a\right)\left(d_{v}+b\right)} .
\end{gathered}
$$

For more details about topological indices and polynomials, we refer to Ref. [35-44].

Benzenoid hydrocarbons play a vital role in our environment, in the food and chemical industries. Benzenoid molecular graphs are systems with deleted hydrogens. It is a connected geometric figure obtained by arranging congruent regular hexagons in a plane, so that two hexagons are either disjoint or have a common edge.

This figure divides the plane into one infinite (external) region and a number of finite (internal) regions. All internal regions must be regular hexagons. Benzenoid systems are of considerable importance in theoretical chemistry, because they are the natural graph representation of benzenoid hydrocarbons. A vertex of a hexagonal system belongs to three hexagons, at most. A vertex shared by three hexagons is called an internal vertex [45].

In this paper we study five benzenoid systems. These are zigzag, rhombic, triangular, hourglass and jaggedrectangle benzenoid systems.

\section{Main results}

\subsection{Zagreb polynomials of triangular benzenoid system}

In this section, we present our computational results. In terms of chemical graph theory and mathematical chemistry, we associate a graph with the molecular structure, where vertices correspond to atoms and edges to bonds. Triangular benzenoid system is shown in Figure 1. In the following theorem we compute M-polynomial of triangular benzenoid system.

\section{Theorem 1}

Let $T_{p}$ be a triangular benzenoid system where $p$ shows the number of hexagons in the base graph and total number of hexagons in $T_{p}$ is $\frac{1}{2} p(p+1)$. Then

1. $M_{3}\left(T_{p}, x\right)=6+\frac{3}{2} p(p-1)+6(p-1) x$.

2. $M_{4}\left(T_{p}, x\right)=6 x^{8}+6(p-1) x^{10}+\frac{3}{2} p(p-1) x^{18}$.

3. $M_{5}\left(T_{p}, x\right)=6 x^{8}+6(p-1) x^{15}+\frac{3}{2} p(p-1) x^{18}$.

4. $M_{a, b}\left(T_{p}, x\right)=6 p x^{2 a}+6 x^{2 b}+\frac{3}{2} p(p-1) x^{3 a}+$ $3(p-1)\left(6+\frac{3}{2} p\right) x^{3 b}$. 


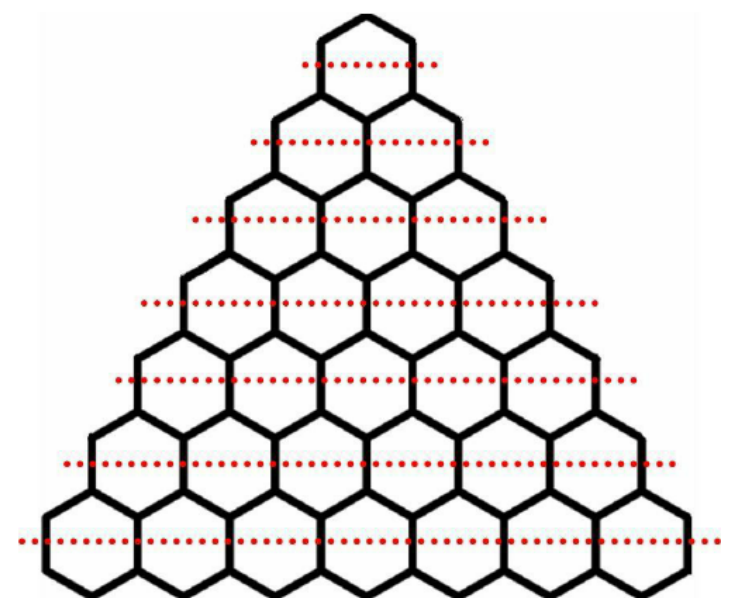

Figure 1: Triangular benzenoid.

5. $M_{a, b}^{\prime}\left(T_{p}, x\right)=6 x^{(2+a)(2+b)}+6(p-1) x^{(2+a)(3+b)}+$ $\frac{3}{2} p(p-1) x^{(3+a)(3+b)}$.

Proof. Let $T_{p}$ be a triangular benzenoid system as shown in Figure 1. Then we have,

$$
\begin{aligned}
& \left|V\left(T_{p}\right)\right|=p^{2}+4 p+1 . \\
& \left|E\left(T_{p}\right)\right|=\frac{3}{2} p(p+3) .
\end{aligned}
$$

The edge set of $T_{p}$ has following three partitions,

$$
\begin{aligned}
& E_{\{2,2\}}=\left\{e=u v \in E\left(T_{p}\right) \mid d_{T_{p}}(u)=2, d_{T_{p}}(v)=2\right\}, \\
& E_{\{2,3\}}=\left\{e=u v \in E\left(T_{p}\right) \mid d_{T_{p}}(u)=2, d_{T_{p}}(v)=3\right\}, \\
& E_{\{3,3\}}=\left\{e=u v \in E\left(T_{p}\right) \mid d_{T_{p}}(u)=3, d_{T_{p}}(v)=3\right\},
\end{aligned}
$$

Now

$$
\begin{aligned}
& \left|E_{\{2,2\}}\right|=6, \\
& \left|E_{\{2,3\}}\right|=6(p-1),
\end{aligned}
$$

And

$\left|E_{\{3,3\}}\right|=\frac{3}{2} p(p-1)$,

\section{Now}

1. $M_{3}\left(T_{p}, x\right)=\sum_{u v \in E\left(T_{p}\right)} x^{d_{u}-d_{v}}=\sum_{u v \in E_{\{2,2\}}\left(T_{p}\right)} x^{2-2}+$ $\sum_{u v \in E_{\{2,3\}}\left(T_{p}\right)} x^{3-2}+\sum_{u v \in E_{\{3,3\}}\left(T_{p}\right)} x^{3-3}=\left|E_{\{2,2\}}\left(T_{p}\right)\right|+$ $\left|E_{\{2,3\}}\left(T_{p}\right)\right| x+\left|E_{\{3,3\}}\left(T_{p}\right)\right|=6+6(p-1) x+$ $\frac{3}{2} p(p-1)=6(p-1) x+\left(\frac{3}{2} p^{2}-\frac{3}{2} p+6\right)$.

2. $M_{4}\left(T_{p}, x\right)=\sum_{u v \in E\left(T_{p}\right)} x^{d_{u}\left(d_{u}+d_{v}\right)}=\sum_{u v \in E_{\{2,2\}}\left(T_{p}\right)} x^{2(2+2)}+$ $\sum_{u v \in E_{\{2,3\}}\left(T_{p}\right)} x^{2(2+3)}+\sum_{u v \in E_{\{3,3\}}\left(T_{p}\right)} x^{3(3+3)}=$ $\left|E_{\{2,2\}}\left(T_{p}\right)\right| x^{8}+\left|E_{\{2,3\}}\left(T_{p}\right)\right| x^{10}+\left|E_{\{3,3\}}\left(T_{p}\right)\right| x^{18}=$ $6 x^{8}+6(p-1) x^{10}+\frac{3}{2} p(p-1) x^{18}$
3. $M_{5}\left(T_{p}, x\right)=\sum_{u v \in E\left(T_{p}\right)} x^{d_{v}\left(d_{u}+d_{v}\right)}=\sum_{u v \in E_{\{2,2\}}\left(T_{p}\right)} x^{2(2+2)}+$ $\sum_{u v \in E_{\{2,3\}}\left(T_{p}\right)} x^{3(2+3)}+\sum_{u v \in E_{\{3,3\}}\left(T_{p}\right)} x^{3(3+3)}=$ $\left|E_{\{2,2\}}\left(T_{p}\right)\right| x^{8}+\left|E_{\{2,3\}}\left(T_{p}\right)\right| x^{15}+\left|E_{\{3,3\}}\left(T_{p}\right)\right| x^{18}=$ $6 x^{8}+6(p-1) x^{15}+\frac{3}{2} p(p-1) x^{18}$.

4. $M_{a, b}\left(T_{p}, x\right)=x^{\left(a d_{u}+b d_{v}\right)}=$ $\sum_{u v \in E_{\{2,2\}}\left(T_{p}\right)} x^{2 a+2 b}+\sum_{u v \in E_{\{3,3\}}\left(T_{p}\right)} x^{3 a+3 b}=\sum_{u v \in E_{\{2,3\}}\left(T_{p}\right)} x^{2 a+3 b}+\mid$ $\left|E_{\{2,3\}}\left(T_{p}\right)\right| x^{2 a+3 b}+\left|E_{\{3,3\}}\left(T_{p}\right)\right| x^{3 a+3 b}=6 x^{2 a+2 b}+$ $6(p-1) x^{2 a+3 b}+\frac{3}{2} p(p-1) x^{3 a+3 b}=6 p x^{2 a}+6 x^{2 b}+$ $\frac{3}{2} p(p-1) x^{3 a}+(p-1)\left(6+\frac{3}{2} p\right) x^{3 b}$.

5. $M^{\prime}{ }_{a, b}\left(T_{p}, x\right)=\sum^{\left(d_{u}+a\right)\left(d_{v}+b\right)}=$ $\sum_{u v \in E_{\{2,2\}}\left(T_{p}\right)} x^{(2+a)(2+b)}+\sum_{u v \in E_{\{2,3\}}\left(T_{p}\right)} x^{(2+a)(3+b)}+$
$\sum_{u v \in E_{\{3,3\}}\left(T_{p}\right)} x^{(3+a)(3+b)}=\left|E_{\{2,2\}}\left(T_{p}\right)\right| x^{(2+a)(2+b)}+$
$\left|E_{\{2,3\}}\left(T_{p}\right)\right| x^{(2+a)(3+b)}+\left|E_{\{3,3\}}\left(T_{p}\right)\right| x^{(3+a)(3+b)}=$
$6 x^{(2+a)(2+b)}+6(p-1) x^{(2+a)(3+b)}+\frac{3}{2} p(p-1) x^{(3+a)(3+b)}$.

\section{Zigzag benzenoid system}

Zigzag benzenoid system is denoted by $Z_{n}$, where $n$ is the number of rows in graph of $Z_{n}$ and each row consists of two hexagons as shown in Figure 2.

Zigzag benzenoid system has the following three partitions,

$$
\begin{aligned}
& E_{\{2,2\}}=\left\{e=u v \in E\left(Z_{n}\right) \mid d_{Z_{n}}(u)=2, d_{Z_{n}}(v)=2\right\}, \\
& E_{\{2,3\}}=\left\{e=u v \in E\left(Z_{n}\right) \mid d_{Z_{n}}(u)=2, d_{Z_{n}}(v)=3\right\}, \\
& E_{\{3,3\}}=\left\{e=u v \in E\left(Z_{n}\right) \mid d_{Z_{n}}(u)=3, d_{Z_{n}}(v)=3\right\},
\end{aligned}
$$

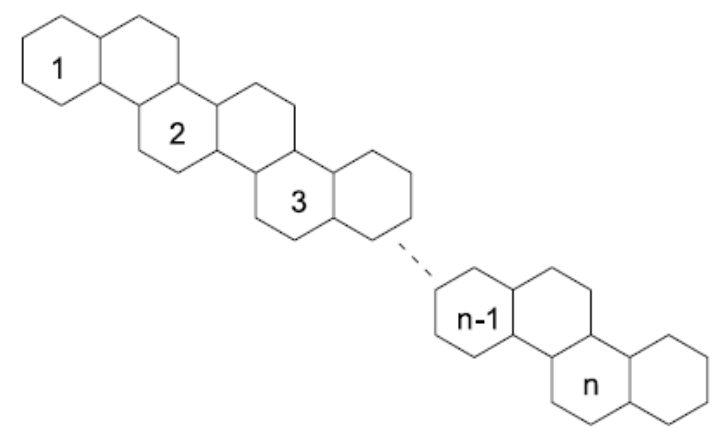

Figure 2: Graph of zigzag benzenoid system $Z_{n}$. 
Now

$$
\begin{aligned}
& \left|E_{\{2,2\}}\left(Z_{n}\right)\right|=2 n+4, \\
& \left|E_{\{2,3\}}\left(Z_{n}\right)\right|=4 n,
\end{aligned}
$$

And $\left|E_{\{3,3\}}\left(Z_{n}\right)\right|=4 n-3$,

So we have following results.

\section{Theorem 2}

Consider a zigzag benzenoid system $Z_{n}$, then

1. $M_{3}\left(Z_{n}, x\right)=4 n x+(6 n+1)$.

2. $M_{4}\left(Z_{n}, x\right)=2(n+2) x^{8}+4 n x^{10}+(4 n-3) x^{18}$.

3. $M_{5}\left(Z_{n}, x\right)=2(n+2) x^{8}+4 n x^{15}+(4 n-3) x^{18}$.

4. $M_{a, b}\left(Z_{n}, x\right)=2(3 n+2) x^{2 a}+2(n+2) x^{2 b}+$ $(4 n-3) x^{3 a}+(8 n-3) x^{3 b}$.

5. $M^{\prime}{ }_{a, b}\left(Z_{n}, x\right)=2(n+2) x^{(2+a)(2+b)}+4 n x^{(2+a)(3+b)}+$ $(4 n-3) x^{(3+a)(3+b)}$.

\section{Rhombic benzenoid aystem}

Take another benzenoid system in which hexagons are arranged to form a rhombic shape $R_{n}$, with $n$ rows of $n$ hexagons as given in Figure 3. Then, it has $2 n(n+2)$ vertices and $3 n^{2}+4 n-1$ edges.

A graph of $R_{n}$ has following three partitions,

$$
\begin{aligned}
& E_{\{2,2\}}=\left\{e=u v \in E\left(R_{n}\right) \mid d_{R_{n}}(u)=2, d_{R_{n}}(v)=2\right\}, \\
& E_{\{2,3\}}=\left\{e=u v \in E\left(R_{n}\right) \mid d_{R_{n}}(u)=2, d_{R_{n}}(v)=3\right\}, \\
& E_{\{3,3\}}=\left\{e=u v \in E\left(R_{n}\right) \mid d_{R_{n}}(u)=3, d_{R_{n}}(v)=3\right\},
\end{aligned}
$$

Now

$$
\begin{aligned}
& \left|E_{\{2,2\}}\left(R_{n}\right)\right|=6, \\
& \left|E_{\{2,3\}}\left(R_{n}\right)\right|=8(n-1),
\end{aligned}
$$

And

$$
\left|E_{\{3,3\}}\left(R_{n}\right)\right|=3 n^{2}-4 n+1 \text {. }
$$

The following theorem follows immediately.

\section{Theorem 3}

Consider the rhombic bezenoid system $R_{n}$, then

1. $M_{3}\left(R_{n}, x\right)=8(n-1) x+\left(3 n^{2}-4 n+7\right)$.

2. $M_{4}\left(R_{n}, x\right)=6 x^{8}+8(n-1) x^{10}+\left(3 n^{2}-4 n+1\right) x^{18}$.

3. $M_{5}\left(R_{n}, x\right)=6 x^{8}+8(n-1) x^{15}+4\left(3 n^{2}-4 n+1\right) x^{18}$.

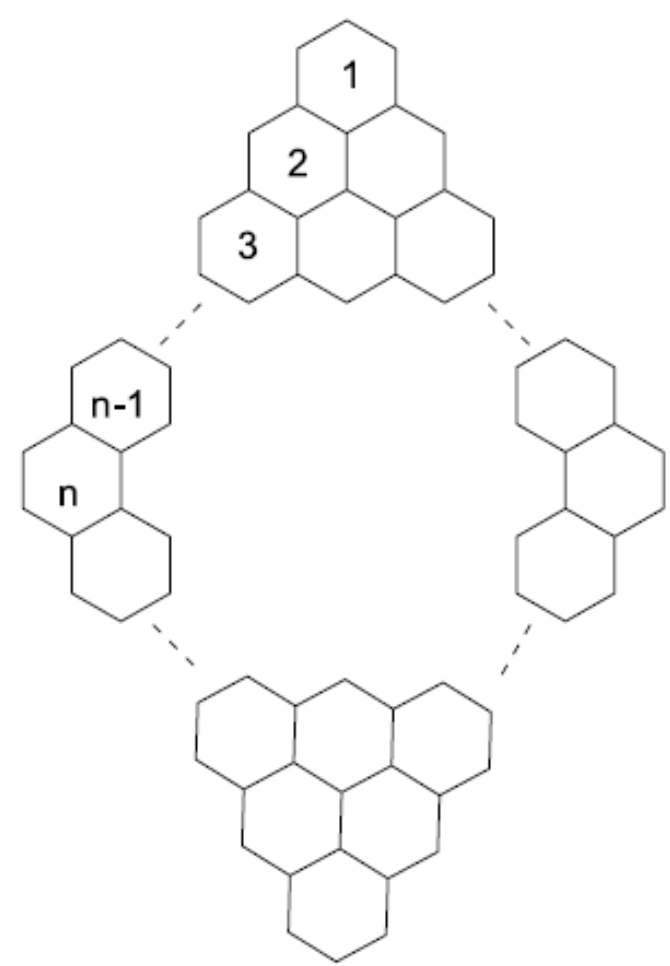

Figure 3: Graph of rhombic benzenoid system with $n$ rows of $n$ hexagons.

4. $M_{a, b}\left(R_{n}, x\right)=2(4 n-1) x^{2 a}+6 x^{2 b}+$ $\left(3 n^{2}-4 n+1\right) x^{3 a}+\left(3 n^{2}-4 n+7\right) x^{3 b}$.

5. $M^{\prime}{ }_{a, b}\left(R_{n}, x\right)=6 x^{(2+a)(2+b)}+8(n-1) x^{(2+a)(3+b)}+$ $\left(3 n^{2}-4 n+1\right) x^{(3+a)(3+b)}$.

\section{Hourglass benzenoid system}

Let $X_{p}$ denotes the benzenoid hourglass, which is obtained from two copies of a triangular benzenoid $T_{p}$ by overlapping their external hexagons. Then we have,

$$
\begin{aligned}
& \left|V\left(X_{p}\right)\right|=2\left(p^{2}+4 p-2\right) \\
& \left|E\left(X_{p}\right)\right|=3 p^{2}+9 p-4
\end{aligned}
$$

The edge set of $X_{p}$ has following three partitions,

$$
\begin{aligned}
& E_{\{2,2\}}=\left\{e=u v \in E\left(X_{p}\right) \mid d_{X_{p}}(u)=2, d_{X_{p}}(v)=2\right\}, \\
& E_{\{2,3\}}=\left\{e=u v \in E\left(X_{p}\right) \mid d_{X_{p}}(u)=2, d_{X_{p}}(v)=3\right\},
\end{aligned}
$$

And

$$
E_{\{3,3\}}=\left\{e=u v \in E\left(X_{p}\right) \mid d_{X_{p}}(u)=3, d_{X_{p}}(v)=3\right\} .
$$

Now

$$
\left|E_{\{2,2\}}\left(X_{p}\right)\right|=8
$$




$$
\left|E_{\{2,3\}}\left(X_{p}\right)\right|=4(3 p-4)
$$

And

$$
\left|E_{\{3,3\}}\left(X_{p}\right)\right|=3 p^{2}-3 p+4
$$

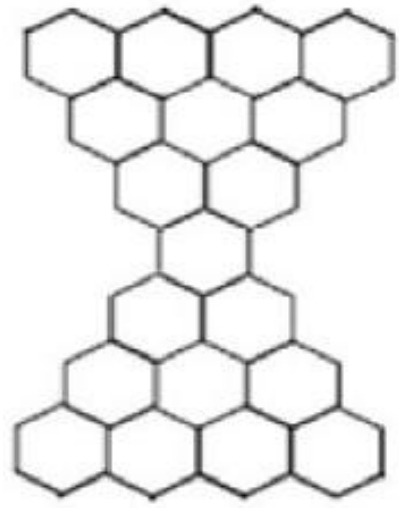

Figure 4: Benzenoid hourglass system.

\section{Theorem 4}

Consider the bezenoid hourglass $X_{p}$, then

1. $M_{3}\left(X_{p}, x\right)=4(3 p-4) x+3\left(p^{2}-p+4\right)$.

2. $M_{4}\left(X_{p}, x\right)=8 x^{8}+4(3 p-4) x^{10}+\left(3 p^{2}-3 p+4\right) x^{18}$.

3. $M_{5}\left(X_{p}, x\right)=8 x^{8}+4(3 p-4) x^{15}+\left(3 p^{2}-3 p+4\right) x^{18}$.

4. $M_{a, b}\left(X_{p}, x\right)=4(3 p-2) x^{2 a}+8 x^{2 b}+$ $\left(3 p^{2}-3 p+4\right) x^{3 a}+3\left(p^{2}+3 p-4\right) x^{3 b}$.

5. $M^{\prime}{ }_{a, b}\left(X_{p}, x\right)=8 x^{(2+a)(2+b)}+4(3 p-4) x^{(2+a)(3+b)}+$ $\left(3 p^{2}-3 p+4\right) x^{(3+a)(3+b)}$.

\section{Benzenoid jagged-rectangle}

Now we study the benzenoid jagged-rectangle shown in Figure 5.

Let $B_{p, q}$ denotes a benzenoid system jagged-rectangle for all $p, q \in N-1$. A Benzenoid jagged-rectangle forms a rectangle and the number of benzenoids called in each chain alternate $p$ and $p-1$. The edge set of $B_{p, q}$ has following three partitions,

$E_{\{2,2\}}=\left\{e=u v \in E\left(B_{p, q}\right) \mid d_{B_{p, q}}(u)=2, d_{B_{p, q}}(v)=2\right\}$, $E_{\{2,3\}}=\left\{e=u v \in E\left(B_{p, q}\right) \mid d_{B_{p, q}}(u)=2, d_{B_{p, q}}(v)=3\right\}$, $E_{\{3,3\}}=\left\{e=u v \in E\left(B_{p, q}\right) \mid d_{B_{p, q}}(u)=3, d_{B_{p, q}}(v)=3\right\}$,

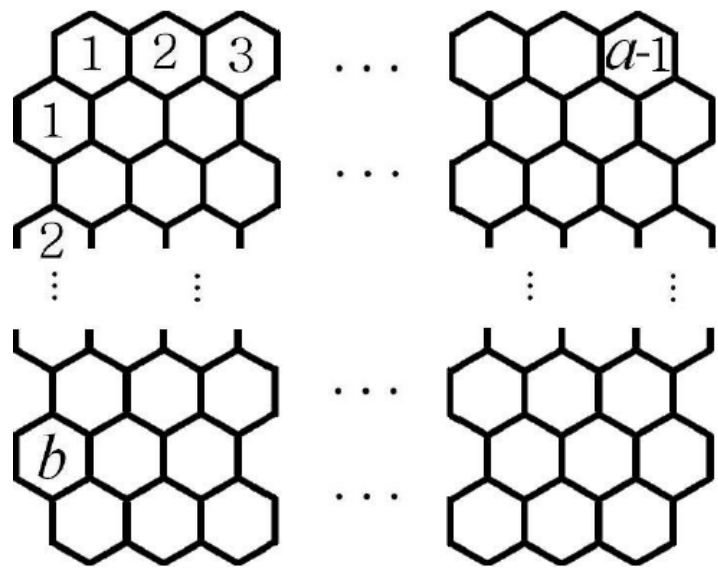

Figure 5: Benzenoid jagged-rectangle system.

Now

$$
\begin{aligned}
& \mid E_{\{2,2\}}\left(B_{p, q)}\right)=2 q+4, \\
& \mid E_{\{2,3\}}\left(B_{p, q)}\right)=4 p+4 q-4
\end{aligned}
$$

And

$$
\left|E_{\{3,3\}}\left(B_{p, q}\right)\right|=6 p q+p-5 q-4 .
$$

Hence we have the following theorem.

\section{Theorem 5}

Consider the bezenoid jagged-rectangle $B_{p, q}$, then

1. $M_{3}\left(B_{p, q}, x\right)=4(p+q-1) x+(6 p q+p-3 q)$.

2. $M_{4}\left(B_{p, q}, x\right)=2(q+2) x^{8}+4(p+q-1) x^{10}+$ $(6 p q+p-5 q-4) x^{18}$.

3. $M_{5}\left(B_{p, q}, x\right)=2(q+2) x^{8}+4(p+q-1) x^{15}+$ $(6 p q+p-5 q-4) x^{18}$.

4. $M_{a, b}\left(B_{p, q}, x\right)=2(2 p+3 q) x^{2 a}+2(q+2) x^{2 b}+$ $4(p+q-1) x^{3 a}+3(6 p q+5 p-q-8) x^{3 b}$.

5. $M_{a, b}^{\prime}\left(B_{p, q}, x\right)=2(q+2) x^{(2+a)(2+b)}+$ $4(p+q-1) x^{(2+a)(3+b)}+(6 p q+p-5 q-4) x^{(3+a)(3+b)}$.

\section{Conclusion}

Topological indices are numbers associated with graphs of chemical compound and help to predict many properties of understudy chemical compound. Polynomials associated with the graph of chemical compound help to compute topological indices, for example Hosaya polynomial help to compute Wiener index, Hyper Wiener index etc. M-polynomial can be used to compute Zagreb indices, Randić index, symmetric division index, harmonic 
index, inverse sum index, augmented Zagreb index. Similarly first, second and third Zagreb polynomial help to compute first, second and third Zagreb index. These polynomials also help to understand molecular structure of understudy chemical compound.

Completing Interests: Authors do not have any competing interest.

Acknowledgement: This research is supported by the funds of Dong A University.

\section{References}

[1] Gao W., Siddiqui M.K., Imran M., Jamil M.K., Farahani M.R., Forgotten topological index of chemical structure in drugs, Saudi Pharm J., 2016, 24(3), 258-264.

[2] Gao W., Farahani M.R., Shi L., Forgotten topological index of some drug structures, Acta Medica Mediterranea, 2016, 32, 579585.

[3] Gao W., Wang Y., Wang W., Shi L., The first multiplication atombond connectivity index of molecular structures in drugs, Saudi Pharm. J., 2017, 25(4), 548-555.

[4] Gao W., Wang Y., Basavanagoud B., Jamil M.K., Characteristics studies of molecular structures in drugs, Saudi Pharm. J., 2017, 25(4), 580-586.

[5] Munir M., Nazeer W., Nizami A.R., Rafique S., Kang S.M., Mpolynomials and topological indices of titania nanotubes, Symmetry, 2016, 8(11), 117.

[6] Munir M., Nazeer W., Rafique S., Kang S.M., M-polynomial and degree-based topological indices of polyhex nanotubes, Symmetry, 2016, 8(12), 149.

[7] Ajmal M., Kang S.M., Nazeer W., Munir M., Jung C.Y., Some Topological Invariants of the Möbius Ladders, Global J. Pure Appl. Math., 2016, 12(6), 5317-5327.

[8] Munir M., Nazeer W., Rafique S., Nizami A.R., Kang S M., Some Computational Aspects of Boron Triangular Nanotubes, Symmetry, 2017, 9(1), 6.

[9] Gao W., Younas M., Adeel M., Virk A.R., Nazeer W., Some Reverse Degree-Based Topological Indices and Polynomials of Dendrimers, Mathematics, 2018, 6(10), 214.

[10] Gao W., Younas M., Farooq A., Mahboob A., Nazeer W., MPolynomials and Degree-Based Topological Indices of the Crystallographic Structure of Molecules, Biomolecules, 2018, 8(4), 107.

[11] Huang,Y., Liu B., Gan L., Augmented Zagreb index of connected graphs, MATCH Commun. Math. Comput. Chem., 2012, 67(2), 483-494.

[12] Nazeer W., Farooq A., Younas M., Munir M., Kang S., On Molecular Descriptors of Carbon Nanocones. Biomolecules, 2018, 8(3), 92.

[13] Gutman I., Trinajstić N., Graph theory and molecular orbitals. Total $\varphi$-electron energy of alternant hydrocarbons, Chem. Phys. Lett., 1972, 17(4), 535-538.
[14] Gutman I., Randić B., Trinajstić N., Wilcox Jr C.F., Graph theory and molecular orbitals. XII. Acyclic polyenes, J. Chem. Phys., 1975, 62(9), 3399-3405.

[15] Balaban A.T., Motoc I., Bonchev D., Mekenyan O., Topological indices for structure-activity correlations, In: Steric effects in drug design, 1983, 21-55, Springer, Berlin, Heidelberg.

[16] Das K.C., Gutman I., Some properties of the second Zagreb index, MATCH Commun. Math. Comput. Chem., 2004, 52(1), 3-1.

[17] Gutman I., Das K.C., The first Zagreb index 30 years after, MATCH Commun. Math. Comput. Chem., 2004, 50(1), 83-92.

[18] Nikolić S., Kovačević G., Miličević A., Trinajstić N., The Zagreb indices 30 years after, Croatica Chemical Acta, 2003, 76(2), 113124.

[19] Zhou B., Remarks on Zagreb indices, MATCH Commun. Math. Comput. Chem., 2007, 57, 591-596.

[20] Das K. C., Sharp bounds for the sum of the squares of the degrees of a graph, Kragujevac J. Math., 2003, 25(25), 19-41.

[21] Došlic T., Furtula B., Graovac A., Gutman I., Moradi S., Yarahmadi Z., On vertex-degree-based molecular structure descriptors, MATCH Commun. Math. Comput. Chem., 2011, 66(2), 613626.

[22] Fath-Tabar G.H., Old and new Zagreb indices of graphs, MATCH Commun. Math. Comput. Chem., 2011, 65(1), 79-84.

[23] Hansen P., Mélot H., Gutman I., Variable neighborhood search for extremal graphs 12: a note on the variance of bounded degrees in graphs, Grouped'étudeset de recherche en analyse des decisions., 2004 HEC Montréal.

[24] Liu B., Gutman I., Upper bounds for Zagreb indices of connected graphs, MATCH Commun. Math. Comput. Chem., 2006, 55, 439446.

[25] Zhang S., Zhang H., Unicyclic graphs with the first three smallest and largest first general Zagreb index, MATCH Commun. Math. Comput. Chem., 2006, 55(20), 06.

[26] Zhou B., Zagreb indices, MATCH-Communications in Mathematical and in Computer Chemistry., 2004, (52), 113-118.

[27] Zhou B., Remarks on Zagreb indices, MATCH Commun. Math. Comput. Chem., 2007, 57, 591-596.

[28] Zhou B., Gutman I., Further properties of Zagreb indices, MATCH Commun. Math. Comput. Chem., 2005, 54, 233-239.

[29] Fath-Tabar G.H., Zagreb Polynomial and Pi Indices of some Nano Structures, Digest J. Nanomat. Biostr., 2009, 4(1), 189-191.

[30] Bindusree A.R., Cangul I.N., Lokesha V., Cevik A.S., Zagreb polynomials of three graph operators, Filomat, 2016, 30(7), 19791986.

[31] Albertson M.O., The irregularity of a graph, Ars Combinatoria, 46, 219-225.

[32] Zhou B., Luo W., On irregularity of graphs, Ars Combinatoria, 2008, 88, 55-64.

[33] Luo W., Zhou B., On the irregularity of trees and unicyclic graphs with given matching number, Utilitas Math., 2010, 83, 141-147.

[34] Bindusree A.R., Cangul I.N., Lokesha V., Cevik A.S., Zagreb polynomials of three graph operators, Filomat., 2016, 30(7), 19791986.

[35] Alaeiyan M., Farahani M.R., Jamil M.K., Computation of the fifth geometric-arithmetic index for polycyclic aromatic hydrocarbons $\mathrm{PAH}_{k}$, Appl. Math. Nonlin. Sci., 2016, 1(1), 283-290.

[36] Jamil M.K., Farahani M.R., Imran M., Malik M.A., Computing eccentric version of second zagreb index of polycyclic aromatic hydrocarbons $\mathrm{PAH}_{k}$, Appl. Math. Nonlin. Sci., 2016, 1(1), 247-252. 
[37] Farahani M.R., Jamil M.K., Imran M., Vertex Plv topological index of titania carbon nanotubes TiO2 (m, n), Appl. Math. Nonlin. Sci., 2016, 1(1), 175-182.

[38] Gao W., Zali M.R., Degree-based indices computation for special chemical molecular structures using edge dividing method, Appl. Math. Nonlin. Sci., 2016, 1(1), 94-117.

[39] Basavanagoud B., Gao W., Patil S., Desai V.R., Mirajkar K.G., Balani P., Computing First Zagreb index and F-index of New Cproducts of Graphs, Appl. Math. Nonlin. Sci., 2017, 2(1), 285298.

[40] Lokesha V., Deepika T., Ranjini P.S., Cangul I.N., Operations of Nanostructures via SDD, ABC4 and GA5 indices, Appl. Math. Nonlin. Sci., 2017, 2(1), 173-180.

[41] Hosamani S.M., Kulkarni B.B., Boli R.G., Gadag V.M., QSPR analysis of certain graph theocratical matrices and their corresponding energy, Appl. Math. Nonlin. Sci., 2017, 2(1), 131-150.
[42] Sardar M.S., Zafar S., Zahid Z., Computing topological indices of the line graphs of Banana tree graph and Firecracker graph, Appl. Math. Nonlin. Sci., 2017, 2(1), 83-92.

[43] Basavanagoud B., Desai V.R., Patil S., $(\beta, \alpha)$ - Connectivity Index of Graphs, Appl. Math. Nonlin. Sci., 2017, 2(1), 21-30.

[44] Ramane H.S., Jummannaver R.B., Note on forgotten topological index of chemical structure in drugs, Appl. Math. Nonlin. Sci., 2016, 1(2), 369-374.

[45] Ali A., Nazeer W., Munir M., Kang S.M., M-Polynomials And Topological Indices Of Zigzag And Rhombic Benzenoid Systems, Open Chemistry, 2018, 16(1), 73-78. 